\title{
Risk Factors Associated with Prostate Hyperplasia at Prof. Dr. W.Z. Johannes Hospital
}

\author{
Indri W. Misnadin, Apris A. Adu, Indriati A. Tedju Hinga \\ Epidemiology and Biostatistics, School of Public Health, \\ Universitas Nusa Cendana, Kupang
}

\begin{abstract}
Background: The increase of Indonesia's population life expectancy causes the increase of advanced age people. This issued resulted in increasing of degenerative diseases such as Hyperplasia Prostate which is the second biggest disease in urology clinic in Indonesia. This study aimed to determine the risk factors in the form of age, smoking, alcoholic consumption, physical exercise, cholesterol, and diabetes mellitus associated to hyperplasia prostate cases at Prof.Dr. W. Z. Johannes, Hospital Kupang.

Subjects and Method: This was an observational analytic study with case control design. A total of the samples were 68 man were collected by random sampling technique. Dependent variable was prostate hyperplasia. Independent variables were age, smoking, phisycal exercise, alcohol consumption and diabetes mellitus. The data were analyzed by Chi Square.

Results: This research showed that risk associated the risk factors were age $(\mathrm{OR}=12.63 ; 95 \% \mathrm{CI}=$ 2.60 to 61.37; $\mathrm{p}<0.001)$, smoking $(\mathrm{OR}=3.52 ; 95 \% \mathrm{CI}=1.27$ to $9.7 ; \mathrm{p}=0.026)$, physical exercise $(\mathrm{OR}=3.38 ; 95 \% \mathrm{CI}=1.25$ to $9.16 ; \mathrm{p}=0.014)$, and cholesterol level $(\mathrm{OR}=3.88 ; 95 \% \mathrm{CI}=1.41$ to 10.66 ; $\mathrm{p}=0.007)$. There was no association on alcohol consumption $(\mathrm{OR}=1.33 ; 95 \% \mathrm{CI}=0.47$ to 3.78 ; $\mathrm{p}=0.595)$ and diabetes mellitus $(\mathrm{OR}=0.88 ; 95 \% \mathrm{CI}=0.32$ to $2.39 ; \mathrm{p}=0.798)$.

Conclusion: Increase prevention efforts such as screening prostate specific antigen socialization and non-communicable diseases as a prevention in the future.
\end{abstract}

Keywords: prostate hyperplasia, risk factors

\section{Correspondence:}

Indri W. Misnadin, Apris A. Adu, Indriati A. Tedju Hinga. Epidemiology and Biostatistics, School of Public Health, Universitas Nusa Cendana, Kupang

\section{BACKGROUND}

Long term planning development of Indonesia Health in 2002 to 2025 with vision of Healthy Indonesia 2025 aims to raise awareness, ability and willingness to live healthily to improve community health status as high as possible realized. Success of health development is characterized by an increased life expectancy from 68.8 in 2004 to 71.7 in 2011.

Increasing the life expectancy has resulted in elderly population. Increasing aging population has led to increase the prevalence of degenerative diseases. Most of the degenerative diseases or the contagious disease affects asthma, Parkinson, kidney disorders, prostate hyperplasia osteoporosis, chronic obstructive pulmonary disease and rheumatoid arthritis.

Benigna Prostatic Hyperplasia (BPH) or hyperplasia prostatic is an enlarged prostate caused by hyperplasia or increase the number of cells. The Office of Health Economic in England has issued estimates of prevalence of symptomatic BPH in England and Wales the next few years. The result stated that symptomatic BPH patients there, amounting around 80,000 patients 
in 1991, increase to 200,000 patients in the year 2031.

Number of benign prostate patient enlargement have not been recorded where the benign prostate disease enlargement into second after tract urinate stone disease in urology clinic, and generally estimated nearly $50 \%$ male in Indonesia over 50 years up to 65 years suffered BPH. In 2010, Indonesia's population reached 200 million. Based on this amount, number of male aged 50 years and above the sum of 5 million inhabitants, it can be said that 2.5 million male suffered BPH Indonesia.

In East Nusa Tenggara, recording of the degenerative diseases, especially prostate hyperplasia is still lack. Based on the results of the study baseline prevalence of hospitalized patients in hospitals Prof. Dr. W.Z. Johannes Kupang in 2009 there were 24 cases of prostatic hyperplasia. In 2010 cases of prostatic hyperplasia increased to 38 cases in 2011 dropped to 23 cases. In 2012 cases of prostatic hyperplasia increased again with the number of 41 cases. A total number of prostatic hyperplasia patients are 7 cases in January 2013. Based on the report the prevalence of outpatient prostate hyperplasia number of patients is increasing every year. In 2010 the number of outpatient prostate hyperplasia as many as 874 cases in 2011 increased to 1423 cases and in 2012 increased to 1657 cases. Data per month outpatient prostate hyperplasia in January 2013 amounted to 103 cases, and in February there were 88 cases.

The government has made efforts to prevent and detect the degenerative disease in the community, such as by encouraging an integrated service post and screening elderly patients. Such efforts have certain constraints, because an integrated service post elderly do not run optimally and the lack of promotion of screening patients resulted in ignorance of the community for the early detection by screening, in this case for screening prostatic hyperplasia together with screening for prostate cancer is the Prostate Specific Antigen (PSA).

Several factors determine cause prostatic hyperplasia that levels of substance prostaglandins in the body, levels of testosterone and the conditions of patients in this age, family history, obesity, increaseed blood cholesterol, a diet high in animal fat, lack of exercise, smoking, alcohol, diabetes mellitus, sexual activity, and stress. Based on the description above, researchers interested conducting research entitled "Risk Factors Associated with Prostate Hyperplasia Genesis at Prof. Dr. W.Z. Johannes hospital, Kupang."

This study aimed to determine the relationship between age, smoking, alcohol consumption, exercise, cholesterol and history of diabetes mellitus on the incidence of prostatic hyperplasia.

\section{SUBJECTS AND METHOD}

This was an observational analytic study with case control design. This stydy compared between the study group, namely people who were sick, with a control group of people who were not sick but had characteristics in common with people who were sick or the study group. Comparisons between the study group and the control group, yielding a value ratio, i.e. the proportion of sick people who had risk factors with people who were not sick who had no risk factors. That ratio was called the odds ratio.

This research was conducted at Prof. Dr. W.Z. Johannes Hospital, Kupang and held on January to July 2013 in the outpatient hospital prostatic hyperplasia from January to March 2013, with a large sample of cases of 34 patients and a control sample of 34 patients were taken using simple ran- 
dom sampling technique and interviews using a set of questionnaire and supported by medical records.

The data analysis used univariate and bivariate. Univariate analysis was conducted to elucidate the characteristics of each variable. The bivariate analysis was conducted to determine the strength of association between exposure and disease by calculating the Odds Ratio using a 2x2 table with a confidence level of $95 \%$ and a significance value of $\mathrm{p}<0.05$. The data were analyzed using a computerized system then interpreted and presented in table and narration.

\section{RESULTS}

The univariate analysis included respondents' place of origin, education, occupation, type of respondent control of major diseases treated in Poly Surgery. Based on the results of the bivariate analysis as age, smoking, alcohol consumption, exercise, history of cholesterol and diabetes mellitus can be seen in Table1.

Table 1. Distribution of respondents by genesis risk factors against prostate hyperplasia at Prof. Dr. Z. W. Johannes hospitals, Kupang in 2013.

\begin{tabular}{|c|c|c|c|c|c|c|c|}
\hline \multirow{2}{*}{ Factors } & \multicolumn{2}{|c|}{ Cases } & \multicolumn{2}{|c|}{ Control } & \multirow{2}{*}{ OR } & \multirow{2}{*}{$95 \% \mathrm{CI}$} & \multirow[b]{2}{*}{$\mathbf{p}$} \\
\hline & $\mathbf{n}$ & $\%$ & $\mathbf{n}$ & $\%$ & & & \\
\hline \multicolumn{8}{|l|}{ Age } \\
\hline$\geq 50$ year & 32 & 94.1 & 19 & $55 \cdot 9$ & \multirow[t]{2}{*}{12.63} & \multirow[t]{2}{*}{2.6 to 61.38} & \multirow[t]{2}{*}{$<0.001$} \\
\hline$<50$ year & 2 & 5.9 & 15 & 44.1 & & & \\
\hline \multicolumn{8}{|l|}{ Smoking } \\
\hline Yes & 19 & $55 \cdot 9$ & 9 & 26.5 & $3 \cdot 5^{2}$ & \multirow[t]{2}{*}{1.27 to 9.75} & \multirow[t]{2}{*}{0.014} \\
\hline No & 15 & 44.1 & 25 & 73.5 & & & \\
\hline \multicolumn{8}{|c|}{ Alcohol Consumption } \\
\hline Yes & 11 & 32.4 & 9 & 26.5 & 1.32 & \multirow[t]{2}{*}{0.47 to 3.79} & \multirow[t]{2}{*}{0.595} \\
\hline No & 23 & 67.6 & 25 & $73 \cdot 5$ & & & \\
\hline \multicolumn{8}{|l|}{ Exercises } \\
\hline$<3$ times a week & 21 & 61.8 & 11 & 32.4 & \multirow[t]{2}{*}{$3 \cdot 378$} & \multirow[t]{2}{*}{1.25 to 9.16} & \multirow[t]{2}{*}{0.015} \\
\hline$\geq 3$ times a week & 13 & 38.2 & 23 & 67.6 & & & \\
\hline \multicolumn{8}{|c|}{ History of Cholesterol } \\
\hline$>5.72 \mathrm{mmol} / \mathrm{L}$ & 24 & 70.6 & 13 & 38.3 & \multirow[t]{2}{*}{3.87} & \multirow[t]{2}{*}{1.410 to 10.66} & \multirow[t]{2}{*}{0.007} \\
\hline$\leq 5.72 \mathrm{mmol} / \mathrm{L}$ & 10 & 29.4 & 21 & 61.8 & & & \\
\hline \multicolumn{8}{|c|}{ Diabetes Mellitus } \\
\hline Yes & 11 & 32.4 & 12 & $35 \cdot 3$ & \multirow[t]{2}{*}{0.877} & \multirow[t]{2}{*}{0.321 to 2.39} & \multirow[t]{2}{*}{0.798} \\
\hline No & 23 & 67.6 & 22 & 64.7 & & & \\
\hline
\end{tabular}

According to the Table 1, at the age obtained $\mathrm{OR}=12.632 ; \mathrm{p}<0.001$ so it concluded that men aged $\geq 50$ years are at risk of experiencing prostate hyperplasia 13 times more likely than men aged $<50$ years, smoking variable obtained $\mathrm{p}=0.014 ; \mathrm{OR}=$ 3.52 , so it can be concluded that men who smoke are at risk of experiencing prostate hyperplasia 3.5 times greater than men who do not smoke.

Alcohol consumption obtained $\mathrm{p}=$ 0.595, it concluded that alcohol consumption does not have a relationship with the incidence of prostate hyperplasia. Exercises obtained $\mathrm{OR}=3.378 ; \mathrm{p}=0.015$, so it concluded that men who exercised $<3$ times a week had a greater risk of 3 times com- 
pared with men exercising $\geq 3$ times a week. Cholesterol history obtained $\mathrm{OR}=3.87$; $\mathrm{p}=0.007$ so it concluded that men who had cholesterol $>5.72 \mathrm{mmol} / \mathrm{L}$ at risk of developing prostate hyperplasia 4 times more likely than men who have a cholesterol history $\leq 5.72 \mathrm{mmol} / \mathrm{L}$. Diabetes mellitus obtained $\mathrm{p}=0.877$, it concluded that diabetes mellitus may be related to the incidence of prostate hyperplasia.

\section{DISCUSSION}

Increasing age leads to changes in hormonal balance, which is between testosterone and estrogen. The production of testosterone decreases and the conversion of testosterone to estrogen in adipose tissue in the periphery, with the help of aromaterase enzymes, where the properties of estrogen will stimulate the receptor's sensitivity prostate cells until the cells increase in size (hyperplasia in stroma) that will compresse the urethra and impede the flow urine. As people age, there will be a decreese of testicular function (spermatogenesis) which will lead to a progressive decrease of androgen secretion and often do not cause symptoms or complaints from concerned. Someone just feel that there is an enlarged prostate when there is disturbance complaint urinate or urinate.

Based on autopsy figures microscopic changes in the prostate can already be found at the age of 30-40 years. In men aged 50 years and the figure of about 50\% and at the age of 80 years about $80 \%$.

The results showed that the agerelated prostate hyperplasia, where men aged $\geq 50$ years had a higher risk 13 times more likely than men aged $<50$ years. Most respondents prostatic hyperplasia belong to the age group at risk ( $\geq 50$ years) of a total of 32 respondents (94\%) of the total 40 respondents case.
This study conducted by Meissari (2008) states that the age associated to benign prostatic $\mathrm{p}<0.001$. This study also consistent to research conducted by Pawennari (2006) that age $\geq 50$ years the incidence of prostatic hyperplasia associated with $\mathrm{p}<0.001$.

\section{Smoking Association on Prostate Hyperplasia in 2013}

Male smokers have greater risk of $61 \%$ to prostate problems than who did not. Not only in difficulty urinating and erectile dysfunction, had smoker also threatened with death because of the potential growth of tumors in the prostate.

There are possibilities make smokers have a higher risk of prostate enlargement. The factors may include carcinogens in cigarette smoke and also hormone. Research by Stacey Kenfield found an association between smoking and testosterone increasing. This hormone stimulates the prostate enlargement. Enlarged prostate, occurs when cells of the prostate mutate and begin to grow out of control. These cells may spread from the prostate metastatis to other parts of the body, especially the bones and lymph nodes. Nicotine in cigarettes causes angiogenesis of formation of new blood vessels, and it may provide food for tumor to grow, including the prostate.

The result showed that smoking habit associated to prostate hyperplasia and men who smoke have an increased risk 3.519 times greater than men who do not smoke. The fact discovered when the research was 19 cases (67.9\%) had the habit of smoking. Based on the interview, majority of the respondents had smoked for more than five years and can be smoked $\geq 12$ cigarettes per day rod.

The results are consistent with research conducted by Haryoko (2010) which showed that smoking relates to prostate hy- 
perplasia with $\mathrm{p}=0.023$. This study also consistent with research conducted by Pawennari (2006) which showed no relation between smoking and prostate hyperplasia with $\mathrm{p}=0.035$ with the possibility of prostatic hyperplasia in men smoke amounted to 3.64 times greater than men who do not smoke.

\section{Association of Alcohol Consumption on Prostate Hyperplasia in 2013}

Consumption alcohol too much is bad habit. Among them, makes the head dizzy and vomiting, and fatigue. Long-term effects may increase the risk of various disease including breast cancer, oral cancer, heart disease, stroke, prostate, and chronic liver disease. Research shows that alcohol consumption in the high level would damage the mental health, weaken memory, and lower fertility.

Bivariate analysis showed men have a habit of alcohol consumption does not have the risk of getting prostate hyperplasia is greater than men who did not have history of obesity (OR=1.32; 95\% CI=0.799 to 3.9 86). The lack of association between alcohol consumption habits and prostate hyperplasia because of the respondents did not consume alcohol (71\%). The number of respondents who did not consume alcohol in the case group and the control is almost the same, where in 23 respondents (68\%), patients with prostatic hyperplasia not consume alcohol while in patients with prostatic hyperplasia are not 25 respondents (73.5\%) who did not consume alcohol.

Based on Amali (2010) shows that the habit of alcohol consumption was not associated with the prostate hyperplasia with $\mathrm{p}=0.126$. The study also supports research Crystals et al., (2008) states that the roles of alcohol consumption in the enlargement is not clear yet, where the consumption of alcohol on a regular according to the standard can be lower the risk of prostate hyperplasia symptoms become $33 \%$. Safe standard to consuming alcohol according to 2-3 units for women and 3-4 units for men per day (but not every day). One unit of alcohol is equivalent to $300 \mathrm{ml}$ beer, or one small glass of wine. Alcohol, especially red wine has resveratrol, antioxidants, bioflavonoids and polyphenols have the function dilate the arteries and reduce inflammation.

This study is not consistent with research conducted by Gong (2009), which men who drink more than 50 grams of alcohol (equivalent of 50 grams of 4 glasses of beer or four glasses of wine) at risk of developing prostate cancer. In prostate problems, excessive alcohol can neutralize zinc (zinc) and vitamin B6, which both these substances essential for maintaining prostate health, so that it will occur in the prostate if any shortfall Gangguan both substances.

\section{Association the exercises on prostate hyperplasia}

Increasing the degenerative diseases such as heart attack, hypertension, diabetes, cholesterol, making many people know that one reason is the lack of activity on a regular exercise. Exercise has been proven to prevent the emergence of diseases, because the body's metabolism is affected body mass.

The international scale studies have handed the findings of the benefits of exercises for health and disease prevention. Studies conducted by Antonelli (2009) revealed that regular exercise can protect men from prostate cancer. Based on the results, it can be concluded were 190 male participants who had a biopsy of the prostate. The participants were quite active, although just walk for a few hours per week, turned out to have significantly less likely to get prostate cancer. 
The results showed that there was a relationship between exercise habits to prostatic hyperplasia. The results showed that men who have a habit of exercise $<3$ times a week had a greater chance of 3.378 times suffer from prostate hyperplasia than with a sport toxicity $\geq 3$ times a week. The respondents who have a habit to do exercises $<3$ times a week (62\%) compared to the control respondents (32\%). Based on the interview, most respondents did not participate in exercises due to physical conditions that are old, not accustomed to exercise since youth and consider doing the housework as a physical work that is equivalent to the exercises.

The results are consistent with research by Amalia (2010) which states that a health effect on the prostate hyperplasia with $\mathrm{OR}=3.309 ; \mathrm{p}=0.006$. The study also supports research Bouilet (2009) which exercise affects hormonal habit of being able to control excess testosterone to stimulate the cancer and the spread of tumors. Exercise can also help lower blood glucose levels and lower insulin release which causes growth and development tumor.

\section{Associated historical cholesterol on prostate hyperplasia in 2013}

Cholesterol is a sterol metabolites containing fats are commonly found in a cell membrane and circulated in blood plasma. Cholesterol is type of lipid or species that are fatty molecules. Cholesterol has function as an energy source, forming the walls of the cells in the body and as forming of steroid hormones. High Density Lipoprotein (HDL) serves as a cleaner excess of cholesterol in the vessel wall to transport it back to the liver. Low Density Lipoprotein (LDL) or bad cholesterol can lead to attachment of cholesterol in the blood vessel walls.

The results showed that there is a relationship between histories of cholesterol on prostatic hyperplasia. The results showed that men who had cholesterol $>5.72$ $\mathrm{mmol} / \mathrm{L}$ has a chance to 3.877 times greater than that suffered prostate hyperplasia $\leq 5,72$ cholesterol mmol / L. The respondents who have a history of cholesterol 24 respondents $(71 \%)$ compared to the control group 13 respondents (23.2\%).

According to Hogstedt Hammarsten (2004) states that the history of the cholesterol effect on prostate hyperplasia with $\mathrm{p}=0.005$. The study supported by the research by Denti et al., (2006) says that the cholesterol effect on prostate hyperplasia, when cholesterol levels of patients changed after treatment with finasteride medicine to prevent prostate hyperplasia. Cholesterol is the material synthesis of pregnolone the precursor DHEA (dehidroepian-androsteron) to produce testosterone, but if excessive will continue in the disruption of the prostate (Vitahealth, 2004).

\section{Associated Diabetes Mellitus on prostate hyperplasia}

Diabetes mellitus is a disease characterized by elevated blood glucose levels (hyperglycemia) continuous and varied, especially after a meal or a state of chronic hyperglycemia accompanied by a variety of metabolic disorders due to hormonal disturbances, which cause a variety of chronic complications in the eyes, kidneys, and blood vessels, with lesions in the basal membrane in the examination with an electron microscope.

All types of diabetes mellitus have similar symptoms and complications at advanced levels. Long-term complications include cardiovascular disease, chronic renal failure (the main cause of dialysis), retinal damage which can lead to blindness, and nerve damage that can cause impotence and gangrene with risk of amputation. More serious complications are more 
Indonesian Journal of Medicine (2016), 1(1): 50-57

https://doi.org/10.26911/theijmed.2016.01.01.07

common when poor control of blood sugar levels.

Sarma et al., (2007) stated that compared to people without diabetes, men with diabetes are more likely to develop pancreatic cancer and prostate. Whereas in diabetic women had more cases of breast cancer, leukemia, or cervical cancer.

The results showed no association between diabetes and the incidence of prostate hyperplasia. There is a disconnection because most respondents did not suffer from diabetes mellitus (66\%). The number of respondents who did not consume alcohol in the case group and the control is almost the same, where as many as 23 respondents (68\%) patients with prostatic hyperplasia without diabetes mellitus whereas in patients with prostatic hyperplasia are not 22 respondents (64.7\%) who did not suffer from diabetes mellitus.

The results are consistent with research conducted by Amalia (2010) which showed that no significant relationship between diabetes and prostate hyperplasia. In addition, research is also consistent with research conducted by Sarma et al., (2009) which states that no significant association with prostate hyperplasia conducted in white men and black in the United States. Sarma indicates the presence of diabetes may be less related to prostate growth and more related to the dynamic component functions of the lower urinary tract. A maximum flow rate is smaller due to infections of diabetes mellitus in patients with prostatic hyperplasia with diabetes compared to patients with benign prostatic diabetes suffer.

This study is not consistent with research Vikram et al., (2009) which states that there is a relationship between diabetes mellitus and prostate hyperplasia after conducting experiments in mice given a high-fat diet. The mice experienced a pro- liferation in prostate cells and have an enlarged prostate, and after being given pioglitazone (a drug to restore insulin levels to normal) causes an increase in insulin sensitivity thus lowering insulin levels and prostate weight.

Socialization screening the specific prostate antigen and keep records of noncommunicable diseases that can be used as a reference for future prevention. People were expected to avoid or reduce unhealthy lifestyle such as smoking and alcohol consumption, exercising and controlling blood cholesterol levels. In addition to routine medical examination and raise awareness by doing screening. For other researchers are expected to carry out further research on prostate hyperplasia such as analyzing influence or investigate other variables that have not been investigated in this study.

\section{REFERENCE}

Amalia R (2010). Risk Factors Occurrence of Benign Prostate Enlargement (Case Study in Kariadi RS, RS Roemani and RSI Sultan Agung Semarang). Thesis. Semarang: Diponegoro University, 23: 37-40.

Antonelli JA (2009). Exercise and Prostate Cancer Risk in a Cohort of Veterans Undergoing Prostate Needle Biopsy. United States of America.

Bouilet (2009). Cancer-Free Living. Jakarta: Mizan Publika.

Bustan MN (2007). Non-Communicable Epidemiology Diseases. Jakarta: Rineka Copyright, p: 4-188

Chandra B (2008). Methods for Health Research. Jakarta: EGC Book Medical Publishers.

Compiler Team (2012). Profile Hospital Prof.Dr.W.Z.Johannes Kupang.

Denti (2006). Journal of Cancer: Changes in HDL-cholesterol and Llipoprotein 
Lp (a) After 6-Month Treatment with finasteride in Males Affected by benign prostatic hyperplasia (BPH). Italy.

Drafting Team (2010). Development of Economic and Social Beberapa Indicator Indonesia Booklet - BPS Indonesia. August 2010.

Editorial Team Vita Health (2004). Prostate. Jakarta: PT Gramedia Pustaka Utama.

Gong Z (2009). Cancer Journal Volume 115: Alcohol Consumption, Finasteride, and Prostate Cancer Risk. United States: University of California.

Hamawi ML (2010). Histopathology Disease Overview of benign prostatic hyperplasia (BPH) and prostate cancer at the Anatomical Pathology Laboratories Adam Malik Hospital, Medan, Period 2008-2009. Essay. Terrain: University of North Sumatra.

Hammarsten, Hodjedt (2004). Journal of Urology Vol. 3: Clinical, Haemodynamic, Anthropometric, Metabolic and Insulin Profile of Men with HighStage Clinical and High-Grade Prostate Cancer. Sweden.

Hardjowijoto (2003). Guidelines for Management of BPH in Indonesia. (http://www.iaui.or.id/ast/file/bph.pdf)Acces sed on June 18, 2012.

Harnowo (2011). Dies of Prostate Cancer caused of Smoker. (http:/health.detik.com/read/2011/o8/07/120321/ 1698286/763/disclamer.html).

Accessed on May 23, 2013.

Haryoko (2010). Correlation Age and smoke on Retention of Urine Total Incidence in Male Patients with Benign Prostate Hyperplasia (BPH) in hospitals Ulin Banjarmasin period July
2009-February 2010. Thesis. Banjarmasin: University Mangkurat.

Kristal (2008). American Journal of Epidemiology: Dietary Patterns, Supplement Use, and the Risk of symptomatic benign prostatic hyperplasia: Results from the Prostate Cancer Prevention Trial. United States of America.

Meisasari F (2007). Associated of Age with Genesis Benign Prostate Hyperplasia (BPH) at the Chrysanthemum (B2) Hospital Dr. M. Yunus Bengkulu.Thesis. Terrain: University of North Sumatra.

Pawennari I (2006). Associated the Age and Smoking Behavior on Genesis Benign Prostatic Hyperplasia (Case Studies at Dr. Soetomo Hospital).Thesis. Surabaya: Universitas Diponegoro

RI Menkes (2010). The Ministry of Health Decree 264 / Menkes / SK / II / 2010 on Guidelines for Health Problems. Intelegensia Penanggulangan Disorders Degenerative Diseases.

Sarma (2007). Journal Diabetes Care: Associations between Diabetes and Clinical Markers of benign prostatic hyperplasia Among Community-Dwelling Black and White Men. United States of America.

Vikram. (2009). Journal of The Prostate: Increased Cell Proliferation and contractility of the Prostate in Insulin Resistant Rats-linking hyperinsulinemia with Benign Prostate Hyperplasia. United States of America. 